\title{
Laboratory Investigation of Using Calcium Lignosulfonate as an Oxidation Inhibitor in Bitumen
}

\author{
Saeed Fatemi (iD, Jafar Bolouri Bazaz $(\mathbb{D}$, and Seyed Ali Ziaee iD \\ Department of Civil Engineering Engineering Faculty, Ferdowsi University of Mashhad, Mashhad, Iran \\ Correspondence should be addressed to Seyed Ali Ziaee; sa-ziaee@um.ac.ir
}

Received 16 July 2021; Revised 12 December 2021; Accepted 7 January 2022; Published 31 January 2022

Academic Editor: Zhanping You

Copyright ( $\odot 2022$ Saeed Fatemi et al. This is an open access article distributed under the Creative Commons Attribution License, which permits unrestricted use, distribution, and reproduction in any medium, provided the original work is properly cited.

\begin{abstract}
Asphalt mixtures are the major constituent of road constructions. Those mixtures expose to high-temperature levels during the construction process and their life cycle. The bitumen aging occurred because of the harmful effects of elevated temperatures upon the asphalt mixtures, which leads to oxidation, evaporation, and physical hardening within the bitumen structure. The aging phenomenon can intensify the hardness and brittleness of bitumen, which negatively affects the performance of asphalt mixtures. Researchers have investigated different types of bitumen additives to diminish the negative effects of bitumen aging, among which biomass additives are more attractive for researchers because that additives are organic and mainly emanate from waste materials. The current study investigated the effect of calcium lignosulfonate (CLS) at four quantities (i.e., 5\%, 10\%, 15\%, and 20\% by the weight of base bitumen) as an antiaging bitumen additive on physical, workability, thermal susceptibility, rheological, and chemical properties of $60 / 70$ penetration grade bitumen. The results revealed that although the addition of CLS into the bitumen enhanced the rigidity of bitumen against rutting failure at high-temperature conditions, the CLS-modified bitumen was more susceptible to fatigue failure than the virgin bitumen at low-temperature regions. The workability analysis showed that the CLS powder could improve the bitumen's consistency against permanent deformation at high-temperature levels. Although the bitumen's viscosity increased because of CLS modification, the CLS-modified bitumen provided acceptable workability based on the Superpave specifications. Outcomes from the rheological test revealed that the addition of CLS into the bitumen improved the rutting resistance of bituminous mixtures at high-temperature levels. The SARA analysis indicated that the hardening of CLSmodified samples emanated from the formation of asphaltenes within the bitumen because of CLS incorporation. Different types of aging indices, including PRP, SPI, VAI, and AIRF, which were calculated in this research, showed that the presence of CLS within the bitumen could retard the bitumen's aging process.
\end{abstract}

\section{Introduction}

Roads are known as the essential part of the transportation system because they can bring human accessibility, economic development, and social benefits $[1,2]$. Moreover, roads are responsible for their users, including car drivers, pedestrians, and goods, to provide comfort and safety for them $[3,4]$. Nowadays, asphalt mixtures are more in demand than concrete mixtures in road constructions because asphalt mixtures can bring high skid resistance, uniform surface, lower traffic noise generation, and more cost-effectiveness than concrete mixtures [5-7].

Asphalt mixture can be formed by mixing bitumen and crushed aggregates [8]. Between them, bitumen plays a significant role in the characteristics of asphalt mixtures; however, bitumen consists within a range of $5 \%$ of the asphalt mixture's weight $[9,10]$. Bitumen is emanated from the crude oil refining process [11]. Bitumen is responsible for aggregates coating and attaching them together [12]. Moreover, it can protect the asphalt mixtures against environmental factors, including moisture damage, UV radiation, and oxygen $[13,14]$. The environmental factors and traffic loading can negatively affect the bitumen coating of aggregates, leading to the deterioration of the asphalt mixture's performance $[15,16]$. It is worth mentioning that road maintenance can impose a financial burden on governments if the asphalt mixtures do not have a suitable and predicted lifetime [17]. 
Bitumen aging is a detrimental phenomenon that occurs during the construction process and service life of asphalt mixtures [18]. Bitumen aging defines as the effect of hot temperature on the bitumen's chemical components [19]. In general, the chemical composition of bitumen consists of saturates, aromatics, resins, and asphaltenes [20]. Among these, saturates are responsible for bitumen's thermal susceptibility [21]. The liquid part of bitumen emanates from aromatics. Moreover, resins provide adhesiveness and waterproofness features within the asphalt mixtures [22, 23]. Finally, asphaltenes in bitumen create rigidity for bitumen's structure [24]. Resins change to asphaltenes during the aging process; besides, aromatics convert to resins [25]. Then, the brittleness of bitumen increases, leading to endangering the bitumen's service life against fatigue failure [26].

Various types of bitumen modifiers have been considered to use as a bitumen's antiaging additive, such as carbon black, ashes, biomaterials, and multidimensional nanomaterials, some of which can emanate from waste [27-30]. In 2006, Ouyang et al. [31] indicated that zinc oxide $(\mathrm{ZnO} 2)$ powder could improve the bitumen's antiaging behavior. In 2009, Zhang et al. [32] investigated the impacts of carbon black on bitumen's aging properties, and the results showed that carbon black had a positive effect on bitumen aging. In 2011, nanoclay was noticed by You et al. [33], who concluded that the addition of nanoclay into the bitumen could be effective on the high-temperature performance of bitumen; besides, it can postpone the bitumen's oxidation. In 2021, Giustozzi et al. [34] investigated the impact of waste cooking oil as a bitumen's antiaging additive. The results showed that waste cooking oil could significantly improve the bitumen's rheological characteristics; moreover, it could hinder the bitumen's aging.

Due to improving the bitumen's antiaging performance, some researchers have evaluated the feasibility of addition biomass material as an antiaging agent into the bitumen $[35,36]$. The biomass additive can be considered a costeffective bitumen modifier because biomass materials are organic and emanate from living organisms, such as plants and animals [37, 38]. As a biomass additive, lignin has increasingly begun to use as a bitumen modifier [39], because, on the one hand, its generation is estimated more than 50 million tons per year [40], and, on the other hand, the usage of lignin as the bitumen modifier can help to reduce waste materials [41]. Calcium lignosulfonate (CLS) is known as a by-product of the pulp and paper industries [41, 42]. Although CLS has the potential of dissolving in bitumen, limited researches have been conducted to evaluate the usage of CLS as a bitumen's antiaging additive.

\section{Objectives and Scope}

In this study, the effect of CLS on the physical properties, workability potential, thermal susceptibility, and rheological behavior of bitumen was investigated. Changes in chemical components of CLS-modified bitumen were investigated using the SARA test. Moreover, bitumen samples were subjected to the short-term aging process to evaluate the antiaging behavior of CLS powder within the bitumen. The rolling thin-film oven (RTFO) test was considered to simulate the short-term aging process. Experimental examinations were conducted on virgin, CLS-modified, and aged bitumen samples to assess the effect of CLS modification and the aging process upon the bitumen's characteristics. It is worth mentioning that the incorporation of CLS powder into the bitumen was considered according to the CLS-tobitumen (CLS/b) ratios: $0.05,0.10,0.15$, and 0.20 by the weight of bitumen. It is hoped that the outputs reveal that whether the addition of CLS within the bitumen can positively affect the characteristics and antiaging behavior of bitumen or not.

\section{Experimental Materials and Methods}

In the current study, 60/70 penetration grade bitumen was provided from Shargh Oil Refinery (Mashhad, Iran). The basic characteristics of the virgin bitumen are presented in Table 1. CLS powder (CAS No: 8061-52-7), obtained from Lingo Tech South Africa Co. Ltd., was used as a bitumen modifier with $5 \%, 10 \%, 15 \%$, and $20 \%$ by weight of bitumen. The physical appearance of CLS powder was solid with light yellow-brown color. Table 2 represents the physical properties of CLS powder. The molecular structure of CLS is depicted in Figure 1; moreover, the CLS chemical formula is C20H24CaO10S2 [42].

The surface morphology of gold-coated virgin bitumen and CLS powder was analyzed based on the field-emission scanning electron microscopy (FESEM) technique. It can be concluded that the virgin bitumen had a smooth surface; besides, CLS powder had a spherical shape containing a bumpy surface, as shown in Figures 2 and 3.

To investigate the effect of CLS incorporation and aging on the bitumen's properties, first of all, physical tests including penetration, softening point, and torsional recovery tests were conducted on the bitumen samples. Secondly, kinematic and rotational viscosity tests were considered to assess the bitumen's workability potential. After that, bitumen's thermal susceptibility was measured according to penetration index (PI) and penetration viscosity number. At the next step, rheological features of bitumen samples at high-temperature conditions were examined according to the dynamic shear rheometer (DSR) test. Finally, the SARA test determined the chemical components of bitumen samples. The experimental procedure was summarized, as can be seen in Figure 4 .

\section{Sample Preparation}

The incorporation of CLS powder, which was sieved through a No.100 sieve, into the virgin bitumen was conducted using the high-shear mixer at $150^{\circ} \mathrm{C}$. Moreover, the mixing speed and mixing time were adjusted at $3000 \mathrm{rpm}$ and $30 \mathrm{~min}$, respectively [43]. Based on the CLS content which was added to the virgin bitumen, the bitumen samples were coded, as can be seen in Table 3. In order to evaluate the homogeneity of CLS-modified samples, the FESEM technique was used [44]. Figure 5 shows the FESEM images, which were taken from CLS20. On the one hand, it can be found that the CLS 
TABle 1: Properties of the base bitumen.

\begin{tabular}{lccc}
\hline Properties & Units & Standard & Measured values \\
\hline Penetration & $0.1 \mathrm{~mm}$ & ASTM D5 & 63 \\
Softening point & ${ }^{\circ} \mathrm{C}$ & ASTM D36 & 53 \\
Ductility at 25 & $\mathrm{~cm}$ & ASTM D113 & +100 \\
Density & $\mathrm{Gr} / \mathrm{cm}^{3}$ & ASTM D70 & 1.02 \\
Flash point & ${ }^{\circ} \mathrm{C}$ & ASTM D92 & 280 \\
Loosen heating & $\%$ & ASTM D1754 & 0.3 \\
\hline
\end{tabular}

Table 2: Physical characteristics of the CLS used in this study.

\begin{tabular}{lcccrr}
\hline Parameter & Color & Odor & Density $\left(\mathrm{kg} / \mathrm{m}^{3}\right)$ & Melting point $\left({ }^{\circ} \mathrm{C}\right)$ & $P \mathrm{H}$ \\
\hline Test results & Light brown & Very slight odor & 500 & +130 & 7.5 \\
\hline
\end{tabular}

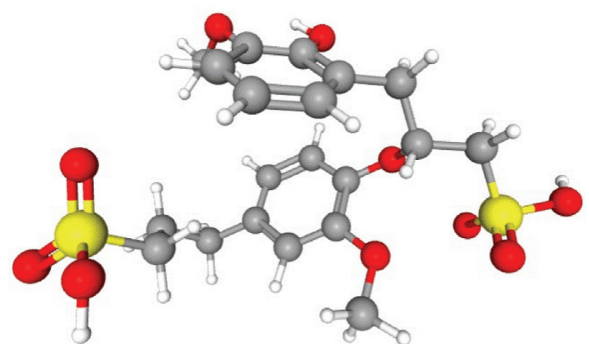

FIgURE 1: Molecular structure of CLS.

powder dissolved into the bitumen. On the other hand, CLS powder changed the bitumen's texture from a smooth surface to a porous surface. The short-term aging was applied on the bitumen samples using the rolling thin-film oven (RTFO) apparatus according to AASHTO T240. It is worth mentioning that bitumen samples were exposed to a temperature of $160^{\circ} \mathrm{C}$ for $75 \mathrm{~min}$ during the aging process [45].

\section{Test Methods}

\subsection{Physical Property Tests}

5.1.1. Penetration Test. The penetration test is known as a conventional physical test [46]. According to ASTM D5, the penetration test was conducted on prepared bitumen samples using a standard needle at a constant temperature $\left(25^{\circ} \mathrm{C}\right)$ [47]. The results of the penetration test can evaluate the bitumen's consistency [48]. If the bitumen samples show a low penetration value, that bitumen can resist the rutting failure at high-temperature regions because of its hardness; however, it can endanger the asphalt mixtures against the fatigue failure at low-temperature conditions $[49,50]$.

5.1.2. Softening Point Test. The softening point value can also be measured to determine the bitumen's physical properties [51]. The softening point test was conducted using standard rings and balls in a water bath based on ASTM D36 [52]. The results can evaluate the bitumen's temperature susceptibility [53]. If the bitumen specimen indicates a high softening point value, that bitumen can preserve its consistency at high-temperature conditions [54].
5.1.3. Torsional Recovery Test. The torsional recovery test can determine the bitumen's elasticity caused by CLS powder [55]. Torsional recovery defines as a bitumen's recovery measured after rotating $180^{\circ}$ at $25^{\circ} \mathrm{C}$ according to the ARRB AG:PT/T112 procedure [56]. Figure 6 depicts the parts of the torsional recovery test apparatus schematically [57]. Equation 1 calculates the torsional recovery percentage $\left(\mathrm{T}_{\mathrm{R}}\right)[56]$.

$$
\mathrm{T}_{\mathrm{R}}=\frac{\mathrm{A}}{180} \times 100,
$$

where A corresponds to the recovered angle, recorded when the band of the specimen is removed and leads to bitumen's recovery for 30 seconds.

\subsection{Workability Performance Tests}

5.2.1. Kinematic Viscosity Test. The bitumen's flow behavior can be evaluated by the kinematic viscosity test based on ASTM D2170 [58]. For this purpose, a glass capillary kinematic viscometer is filled with bitumen; at the next step, the capillary tube is subjected to the specified temperature $\left(135^{\circ} \mathrm{C}\right)$. Finally, the bitumen flows between standard marks through the capillary tube due to bitumen's gravitational force, and the passing time can be achieved [59]. The kinematic viscosity is obtained by multiplying the passing time by the calibration factor of the glass capillary kinematic viscometer tube [60]. Figure 7 shows the kinematic viscosity measurement apparatus.

5.2.2. Rotational Viscosity Test. The bitumen's rotational viscosity (RV) is a key factor of bitumen to ascertain its workability during the mixing and compaction of asphalt mixtures [61]. Based on the procedure described in ASTM D4402, the cylindrical spindle, which contains a constant rotational speed, should be submerged in the bitumen during the RV test [62]. In this research study, the Brookfield rotational viscometer conducted the RV test with the rotational speed of $20 \mathrm{RPM}$ at $135^{\circ} \mathrm{C}$ and $165^{\circ} \mathrm{C}$ to evaluate the bitumen's workability of both virgin and modified samples [63]. The ASTM D4402 recommends that the bitumen's RV values be lower than $3.00 \mathrm{Pas}$ at $135^{\circ} \mathrm{C}$ [64]. 


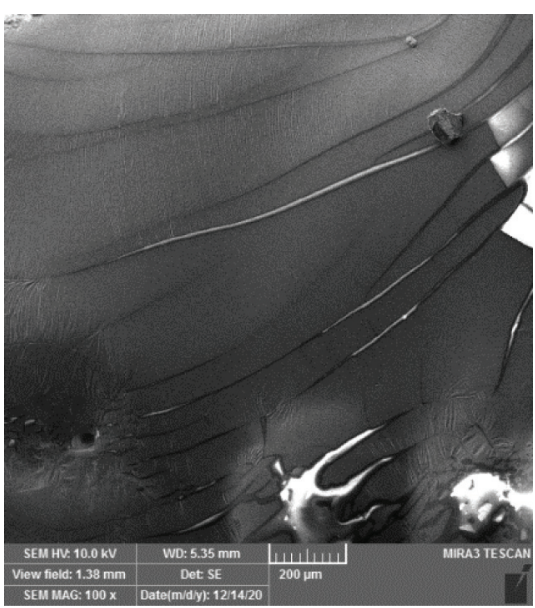

(a)

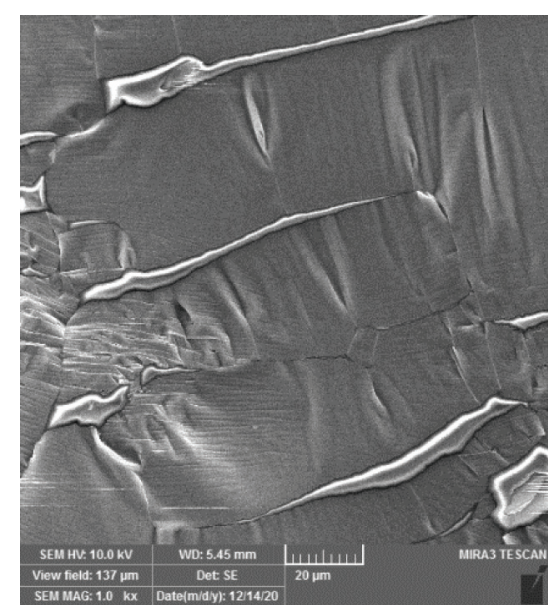

(b)

FIgURE 2: FESEM images of the virgin bitumen, which was taken at (a) $100 \mathrm{x}$ zoom and (b) $1.00 \mathrm{kx}$ zoom.

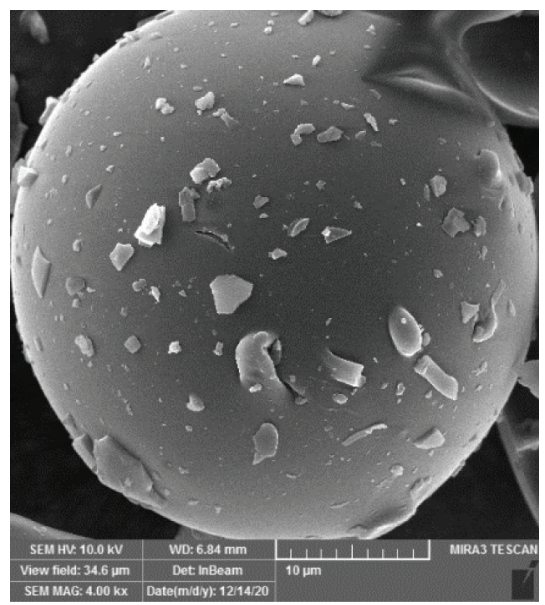

Figure 3: FESEM image was taken at $4.00 \mathrm{kx}$ zoom from the CLS powder.

\subsection{Thermal Susceptibility Analysis}

5.3.1. Penetration Index (PI). The bitumen's temperature susceptibility can be determined by the penetration index (PI) value which depends on the results of penetration and softening point tests [65]. Temperature susceptibility indicates the effect of temperature upon the changes in the bitumen's consistency [66]. The PI was calculated as follows [67]:

$$
\mathrm{PI}=\frac{1952-500 \times \log \left(\text { pen }_{25}\right)-20 \times \mathrm{SP}}{50 \times \log \left(\text { pen }_{25}\right)-\mathrm{SP}-120} .
$$

$\mathrm{Pen}_{25}$ denotes the bitumen's penetration value at $25^{\circ} \mathrm{C}$ in a tenth of millimeters (dmm), and SP presents the bitumen's softening point value in terms of degree Celsius.

It is worth mentioning that the bitumen's PI values fluctuate from around -3 (high-temperature susceptible bitumen) to around +7 (low-temperature susceptibility). Based on previous studies, it can be concluded that if the bitumen contains the PI value between -1 and +1 , it will be favorable for usage in asphalt mixtures [68].
5.3.2. Penetration Viscosity Number (PVN). Besides the penetration index $(\mathrm{PI})$, the penetration viscosity number (PVN) was introduced as an additional option to specify the bitumen's temperature susceptibility based on penetration and kinematic viscosity values [69]. The formula for PVN determination is expressed as follows [70]:

$\mathrm{PVN}=-1.5 \times\left(\frac{4.258-0.7967 \times \log \left(\mathrm{Pen}_{25}\right)-\log (\mathrm{V})}{0.795-0.1858 \times \log \left(\mathrm{Pen}_{25}\right)}\right)$

$\mathrm{Pen}_{25}$ is the penetration value $(\mathrm{dmm})$ measured at $25^{\circ} \mathrm{C}$, and $\mathrm{V}$ is the bitumen's kinematic viscosity value (cSt) recorded at $135^{\circ} \mathrm{C}$.

Based on previous researches, it can be concluded that the bitumen's PVN values range from +0.5 to -2 . Moreover, decreasing the PVN value leads to high-temperature susceptibility [71].

5.4. Rheological Property Test. The elastic, viscous, and viscoelastic portions of bitumen were analyzed by a dynamic shear rheometer (DSR) test [72]. Figure 8 shows the DSR test apparatus. The DSR test is capable of measuring the viscoelastic behavior of bitumen which is affected by different variables, including polymers and temperature levels. Then to investigate the effect of CLS on the rheological behavior of bitumen at high-temperature levels, the DSR test was performed on virgin and CLS-modified bitumen samples [73]. The complex shear modulus $\left(G^{*}\right)$ and the phase angle $(\delta)$ were achieved as outputs of the DSR test, which was conducted upon the $25 \mathrm{~mm}$ bitumen sample discs at a frequency of $10 \mathrm{rad} / \mathrm{sec}$ according to the procedure described in AASHTO T315 [74]. The complex modulus $\left(G^{*}\right)$ expresses the bitumen sample's total resistance against deformation when it exposes to the shear stresses; moreover, the phase angle $(\delta)$ can be defined as the delay between the applied shear stress and the resulting shear strain $[75,76]$. Figure 9 depicts the elastic portion and viscous portion of bitumen. It 


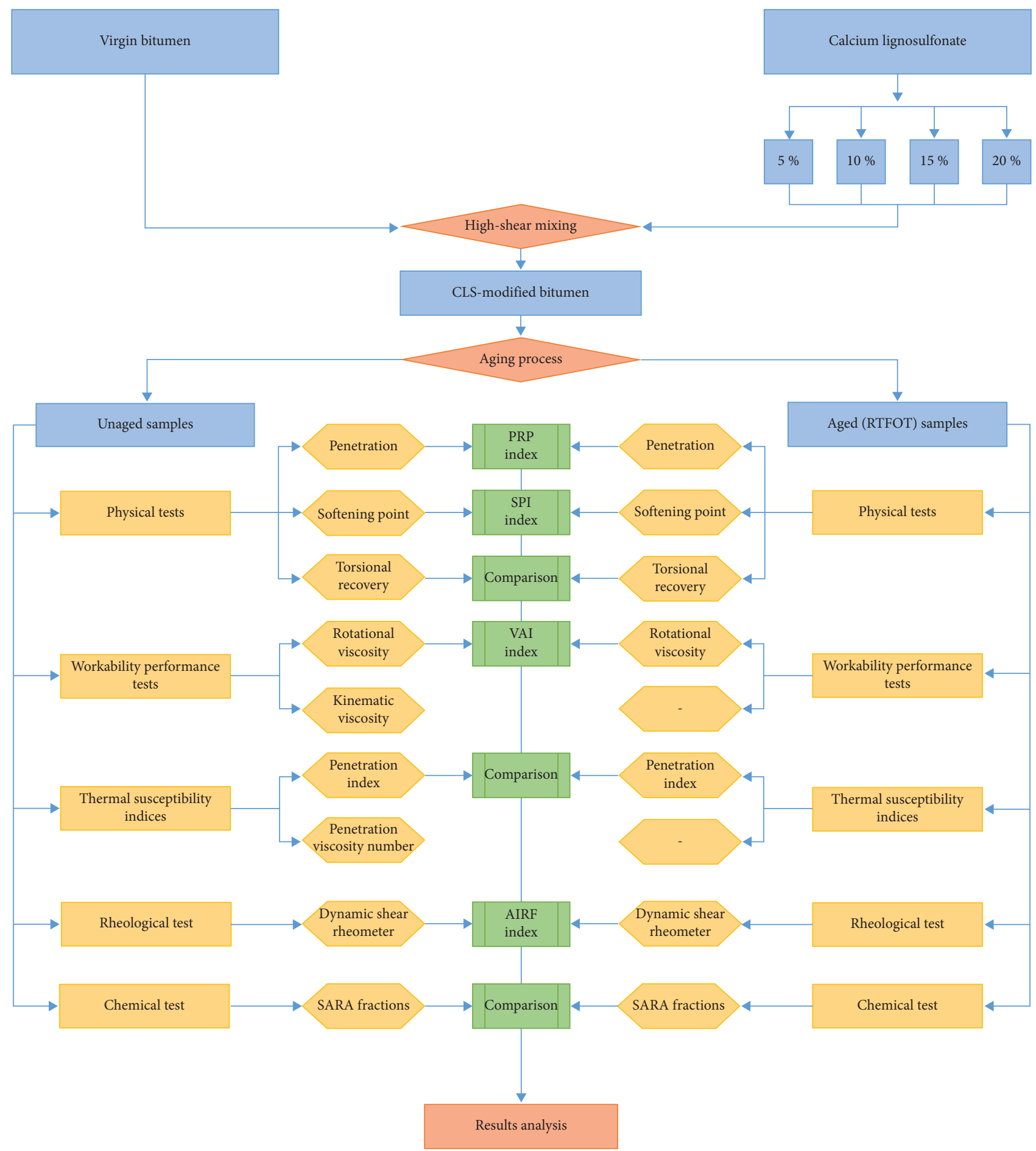

FIgURE 4: Experimental plan scheme.

is worth mentioning that both mentioned portions are correlated to the total shear complex modulus $\left(G^{*}\right)$ and phase angle $(\delta)[74]$.

5.5. SARA Fraction Analysis. In this research, SARA fractions were separated from unaged and aged bitumen samples in accordance with ASTM D4124 [77]. Then to determine bitumen's SARA components, the solvent precipitation and chromatographic column method were used. Based on mentioned separation method, four components, namely, saturates, aromatics, resins, and asphaltenes, were identified within the bitumen [78]. The first component usually forms 5 wt.\% to 15 wt.\% of bitumen. The physical appearance of saturates is liquid and colorless at room temperature. The second fraction takes 30 wt.\% to $45 \mathrm{wt} . \%$ of bitumen; moreover, the color of aromatics is 
TABle 3: Codes of different samples.

\begin{tabular}{lc}
\hline Sample & Code \\
\hline Virgin bitumen & CLS0 \\
Virgin bitumen $+5 \%$ CLS & CLS5 \\
Virgin bitumen $+10 \%$ CLS & CLS10 \\
Virgin bitumen $+15 \%$ CLS & CLS15 \\
Virgin bitumen $+20 \%$ CLS & CLS20 \\
\hline
\end{tabular}

yellow to red at room temperature. Around $30 \mathrm{wt} . \%$ to $40 \mathrm{wt} . \%$ of bitumen is formed by resins that are solid and have dark brown color at room temperature. The black color of bitumen emanates from asphaltenes which usually construct 5 wt. $\%$ to 20 wt.\% of bitumen $[79,80]$.

\section{Results and Discussion}

\subsection{Physical Properties}

6.1.1. Penetration Test. Figure 10 shows the results of the penetration test for bitumen samples. It can be found that when the CLS particles increased from $0 \%$ to $20 \%$, the outputs of the unaged sample decreased dramatically from $62.5 \mathrm{dmm}$ to $42.6 \mathrm{dmm}$. For each bitumen mix type, the aging process could increase the bitumen stiffness because the aging process dwindled the penetration values of aged samples compared with penetration values of unaged specimens. In order to determine the susceptibility of bitumen samples against the aging process, the percent retained penetration (PRP) index was determined based on (4) $[81]$.

$$
\mathrm{PRP}=\frac{\text { Penetration after aging }}{\text { Penetration before aging }} \times 100 \text {. }
$$

The presence of CLS particles within the bitumen had a positive effect on the PRP index of bitumen samples, according to the results presented in Figure 10. Then, CLS particles provided positive effects against the bitumen hardening during the aging process. The bitumen with $15 \%$ CLS showed the lowest susceptibility against aging because that bitumen sample had the highest PRP value.

6.1.2. Softening Point Test. The high-temperature susceptibility of bitumen samples was measured according to the softening point test [53]. Figure 11 shows how the softening point values increased versus the addition of CLS particles within the binder. According to Figure 11, as the content of CLS particles increased, the softening point of bitumen specimens experienced an upward trend. Therefore, CLS particles could increase the bitumen hardening, which led to improvement in the high-temperature performance of bitumen. The highest softening point value of CLS-modified samples was $53^{\circ} \mathrm{C}$, which increased approximately $8 \%$ than the virgin binder. Moreover, the bitumen aging led to an increase in bitumen's stiffness because the softening point values of aged bitumen samples were higher than unaged ones. The effect of aging on the bitumen hardening was calculated based on the softening point index (SPI) (5) [82].
SPI $=$ Aged softening point value - Unaged softening point value.

It is evident from Figure 11 that CLS particles could dwindle the bitumen's stiffness emanated from the aging process because the SPI values of CLS-modified samples were lower than the SPI value of the virgin specimen.

6.1.3. Torsional Recovery Test. The torsional recovery outputs are reported in Figure 12. The results determine the viscoelastic and brittleness of bitumen samples at low-intermediate temperatures [56]. It can be found that the recovered angle and torsional recovery values dropped when the CLS powder was added. For example, the bitumen sample containing 20\% CLS powder recorded the lowest recovered angle and torsional recovery values. Then, it can be deduced that the addition of CLS powder into the bitumen affects the elastic behavior of the bitumen samples at $25^{\circ} \mathrm{C}$, negatively. Meanwhile, CLS powder can degrade the bitumen's fatigue life because the brittleness of CLS-modified samples was higher than virgin bitumen's brittleness.

\subsection{Workability Performance}

6.2.1. Kinematic Viscosity Test. The outputs of the effects of CLS powder on kinematic viscosity of virgin bitumen are plotted in Figure 13 The addition of CLS powder to the virgin bitumen increased the value of kinematic viscosity of the control sample from 339 cSt to $408,431,548$, and 617 cSt with 5 wt.\%, 10 wt.\%, 15 wt.\%, and 20 wt.\% of CLS powder incorporated, respectively. It can be concluded that the CLSmodified bitumen contained higher consistency compared with the virgin bitumen. Then, CLS powder decreased the high-temperature susceptibility of bitumen, which can improve the strength of the asphalt mixture against rutting.

6.2.2. Rotational Viscosity Test. The results of the RV test at $135^{\circ} \mathrm{C}$ and $165^{\circ} \mathrm{C}$ are shown in Figures 14 and 15 , respectively. Compared with the virgin bitumen, the CLS-modified samples recorded higher RV values. Moreover, when the dosage of the CLS was 20\%, the highest RV value was achieved at each specified temperature level. It can be seen that the CLS20 recorded $0.68 \mathrm{Pas}$ and $0.17 \mathrm{Pas}$ at $135^{\circ} \mathrm{C}$ and $165^{\circ} \mathrm{C}$, respectively. As a result, it can be concluded that the CLS particles could increase the stiffness of bitumen at high-temperature conditions. The RV values of all bitumen samples were lower than 3.00 Pa s; therefore, the presence of CLS particles within the bitumen did not negatively affect the bitumen's workability [64]. The viscosity aging index (VAI) was calculated for bitumen samples based on (6) to evaluate the effect of the aging process on the bitumen's viscosity [83].

$\mathrm{VAI}=\frac{\text { Viscosity after aging }- \text { Viscosity before aging }}{\text { Viscosity before aging }} \times 100$.

As Figures 14 and 15 depict, the VAI experienced a downward trend at $135^{\circ} \mathrm{C}$ and $165^{\circ} \mathrm{C}$ when the CLS particles 


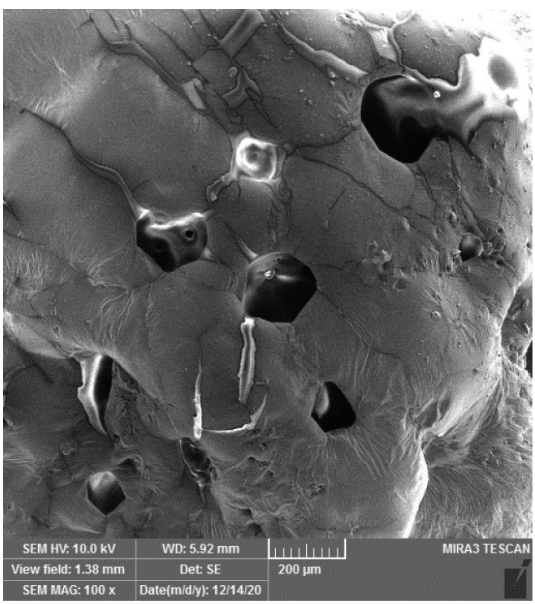

(a)

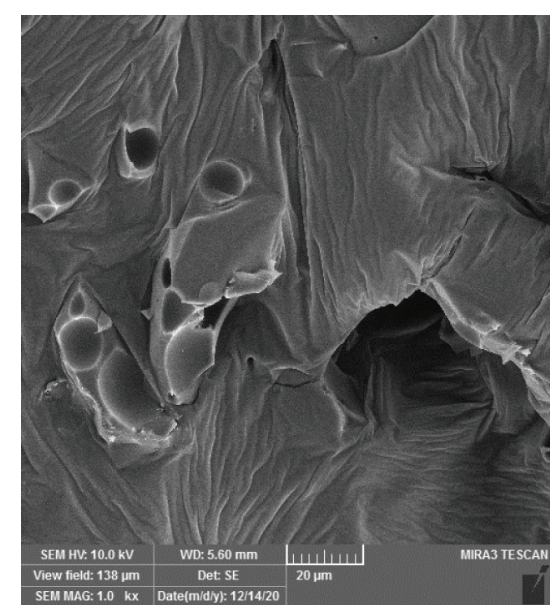

(b)

FIgURE 5: FESEM images of the CLS-modified bitumen, which were taken at (a) $100 \mathrm{x}$ zoom and (b) $1.00 \mathrm{kx}$ zoom.

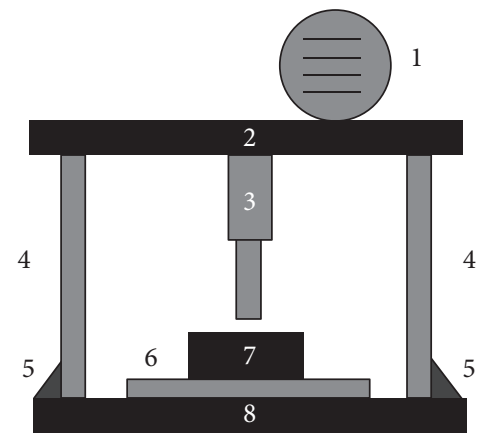

1. Electrical engine

2. Upper board as bearing for the engine

3. Loading rim

4. Columns to support the engine board

5. The welded angles to prevent any lateral movement when the loading rim rotates

6. Degreed plate to measure recovered angle

7. Place for the container of the sample

8. Down board as bearing for the container of the sample and the degreed plate

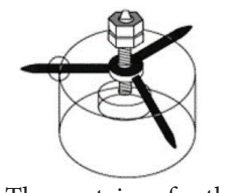

The container for the sample

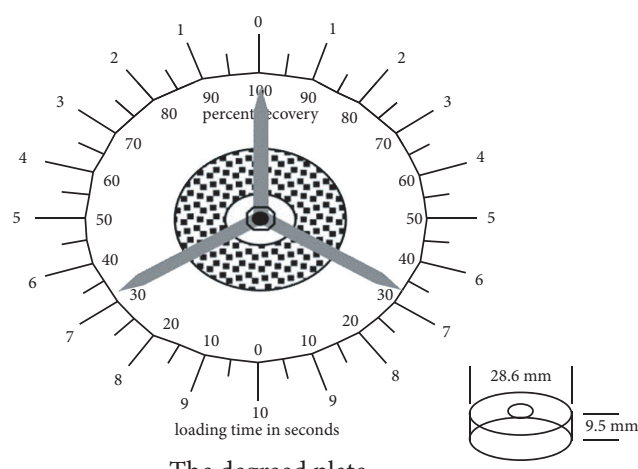

The degreed plate

Figure 6: Components of the torsional recovery test [57].

increased within the bitumen. Then, CLS particles could retard the bitumen's stiffness due to the aging process.

\subsection{Thermal Susceptibility Analysis}

6.3.1. Penetration Index (PI). Figure 16 depicts the PI value of the bitumen sample, which indicates the bitumen's temperature susceptibility [66]. The low PI value denotes bitumen's brittleness, negatively affecting the transverse cracking in low-temperature regions. Moreover, the high PI value shows the high-temperature susceptibility leading to bitumen's softness [68]. As shown in Figure 16, incorporating $5 \%, 10 \%, 15 \%$, and $20 \%$ CLS powder into the bitumen dwindled the PI value of unaged samples to $-0.82,-0.84$, -0.88 , and -0.9 , respectively. CLS-modified samples were more prone to brittleness than the virgin bitumen because the PI value of modified samples experienced a downward trend toward the negative zone. The aging process increased the bitumen's hardness because the PI value of aged specimens decreased toward negative values. Moreover, CLS powder could diminish the bitumen's hardening caused by aging.

6.3.2. Penetration Viscosity Number (PVN). The effect of CLS powder upon the bitumen's thermal susceptibility was measured based on PVN values, as depicted in Figure 17. It can be concluded that the virgin bitumen had the highest temperature susceptibility because its PVN value was the lowest. When CLS content increased from $0 \%$ to $20 \%$, the PVN value experienced an upward trend from -0.97 to -0.52 . 


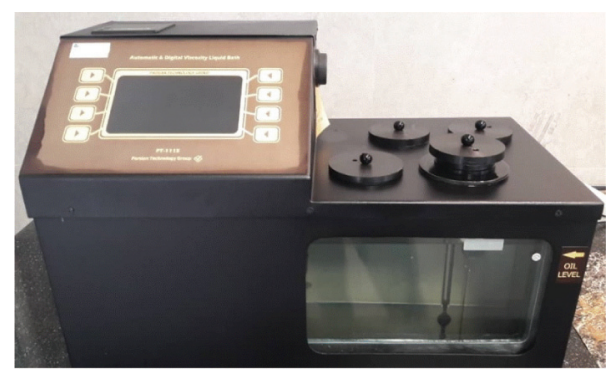

FIgURE 7: Kinematic viscosity test apparatus.

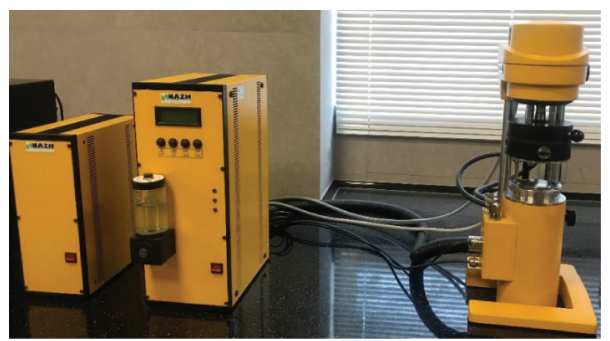

Figure 8: Dynamic shear rheometer (DSR) test device.

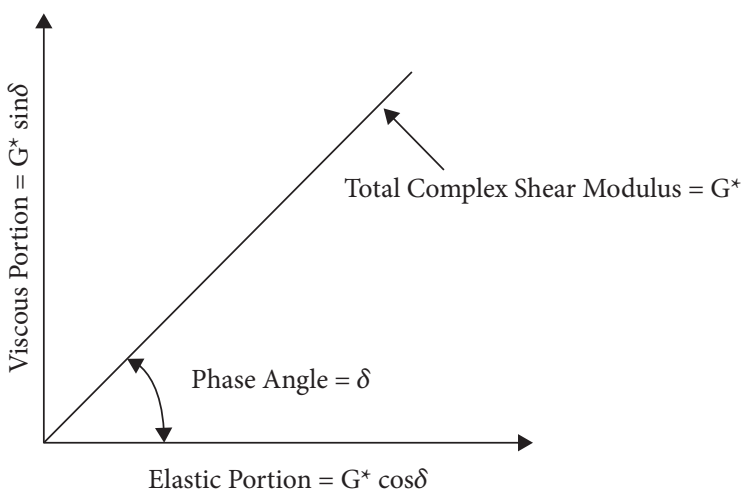

FIGURE 9: Viscous and elastic portions of the bitumen sample [74].

Then, the increase of CLS powder within the bitumen was directly related to bitumen's better thermal stability. As a result, the CLS-modified bitumen can resist more against rutting failure than the virgin bitumen.

6.4. Rheological Properties. Figures 18 and 19 reveal the results of the DSR test for unaged and aged bitumen specimens. It can be found that the complex modulus $\left(G^{*}\right)$ of CLS-modified samples was higher than virgin bitumen. Then, addition of CLS into the bitumen could increase the bitumen's stability against rutting failure. Moreover, the complex modulus $\left(G^{*}\right)$ of all bitumen samples experienced a downward trend when the temperature increased from $58^{\circ} \mathrm{C}$ to $70^{\circ} \mathrm{C}$. At all temperature levels, the maximum complex modulus $\left(G^{*}\right)$ appeared when the CLS dosage was $15 \%$. As depicted in Figure 19, the aging process increased the complex modulus $\left(G^{*}\right)$ of bitumen samples because the aging process could increase the bitumen's hardness.

According to Figure 20 CLS-modified samples had the lower phase angle $(\delta)$ values compared with the virgin bitumen. Therefore, the CLS powder could increase the strength of bitumen against shear stresses [73]. The CLS15 achieved the lowest phase angle $(\delta)$ among all samples at each temperature level, and then, CLS15 had the highest resistance against shear stresses. The phase angle $(\delta)$ values experienced an upward trend when the temperature increased because elevated temperatures increased the viscous behavior of bitumen samples [74]. Figure 21 shows that the phase angle $(\delta)$ of bitumen samples decreased during the aging process because aging could increase the bitumen's hardness.

Due to evaluating the bitumen's rutting resistance for virgin and CLS-modified bitumen samples, the rutting factor $\left(G^{*} / \sin \delta\right)$ was measured, as can be seen in Figure 22 [84]. It can be concluded that the incorporation of CLS into the bitumen could improve the bitumen's resistance against rutting failure. Moreover, when the temperature raised, the rutting factor $\left(G^{*} / \sin \delta\right)$ values of all bitumen specimens dropped. Thus, the high temperature could increase the bitumen's viscous components. Especially at $70^{\circ} \mathrm{C}$, the unaged bitumen samples could not resist the permanent 


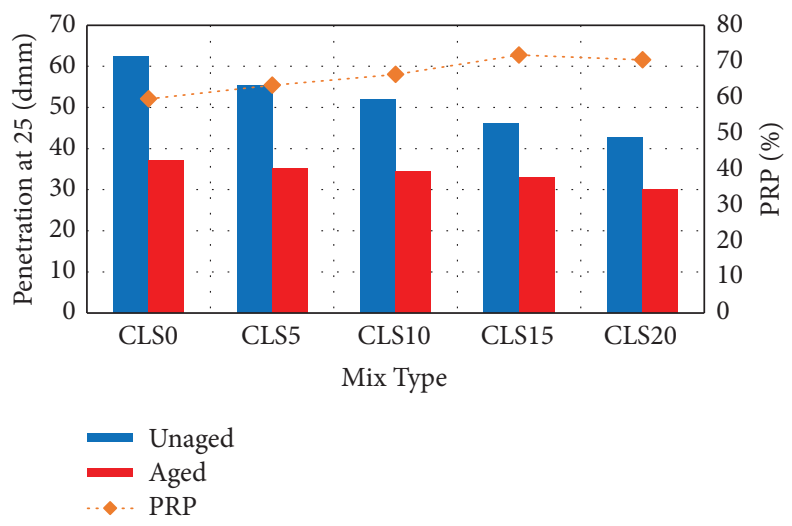

FIGURE 10: Penetration and PRP values of bitumen samples.

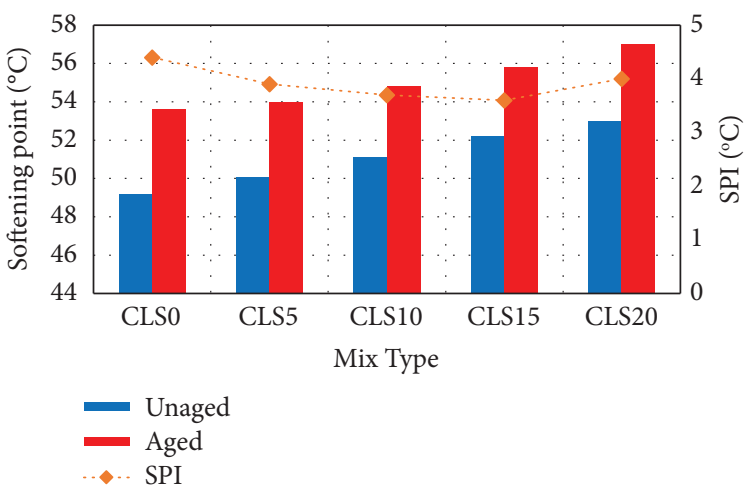

FIGURE 11: Softening point and SPI values of different mix types.

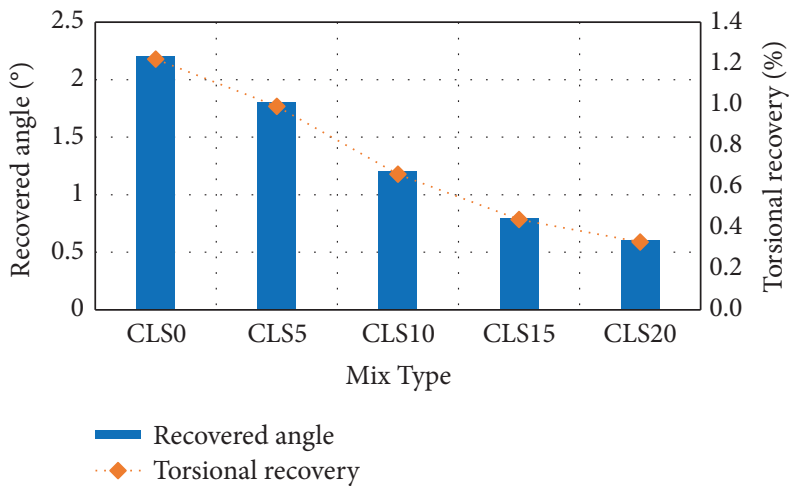

FIGURE 12: Recovered angle and torsional recovery values of virgin and CLS-modified samples.

deformation based on the Superpave specifications because their values were lower than $1.0 \mathrm{kPa}$ [85]. After RTFO aging, the rutting factor of bitumen samples increased compared with unaged bitumen specimens. This meant the aging process could increase the bitumen's hardness. The rutting factor $\left(G^{*} / \sin \delta\right)$ of aged bitumen samples at $70^{\circ} \mathrm{C}$ could not pass the requirement about Superpave specifications because the rutting factor $\left(G^{*} / \sin \delta\right)$ of aged bitumen samples was lower than $2.2 \mathrm{kPa}$ [85].

In order to measure the bitumen's hardness emanated from the aging process, the aging index of the rutting factor (AIRF) was calculated as follows [86]:

$$
\operatorname{AIRF}=\frac{\mathrm{G}^{*} / \sin (\delta)_{\text {aged }}}{\mathrm{G}^{*} / \sin (\delta)_{\text {unaged }}} .
$$

A lower AIRF led to better aging resistance; therefore, the CLS-modified samples had lower susceptibility to aging than the control specimen, as can be seen in Figure 23.

6.5. SARA Fraction Analysis. Figures 24 and 25 illustrate the distribution of bitumen's fractions (i.e., asphaltenes, resins, aromatics, and saturates) based on the SARA analysis before and after the aging process, respectively. The outputs are plotted 


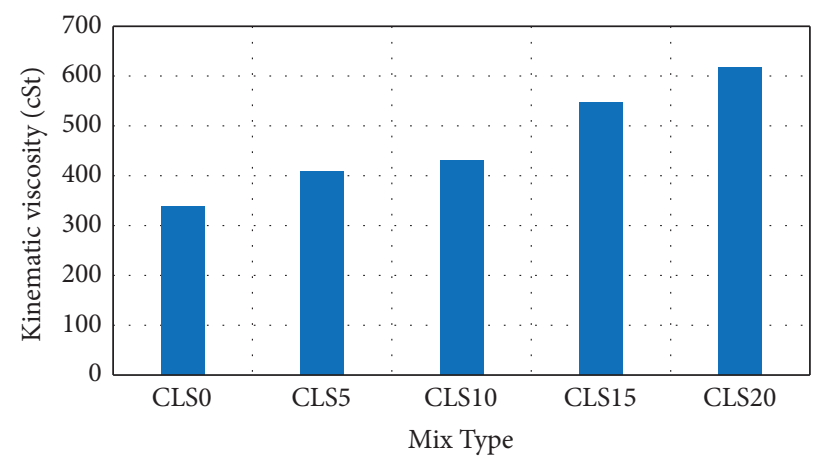

FIGURE 13: Kinematic viscosity results of the bitumen samples.

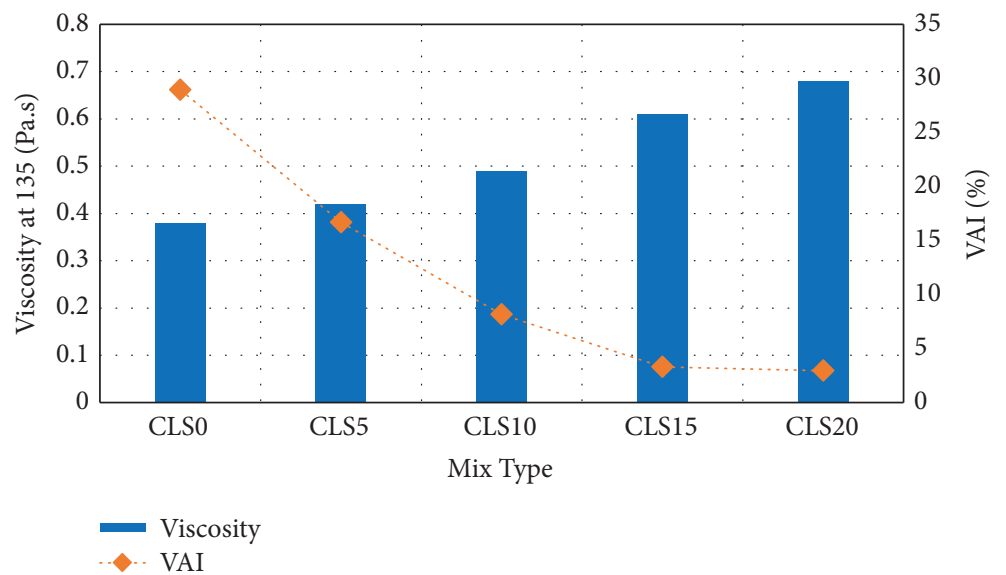

FIgURE 14: Rotational viscosity results and VAI values of bitumen samples (at $135^{\circ} \mathrm{C}$ ).

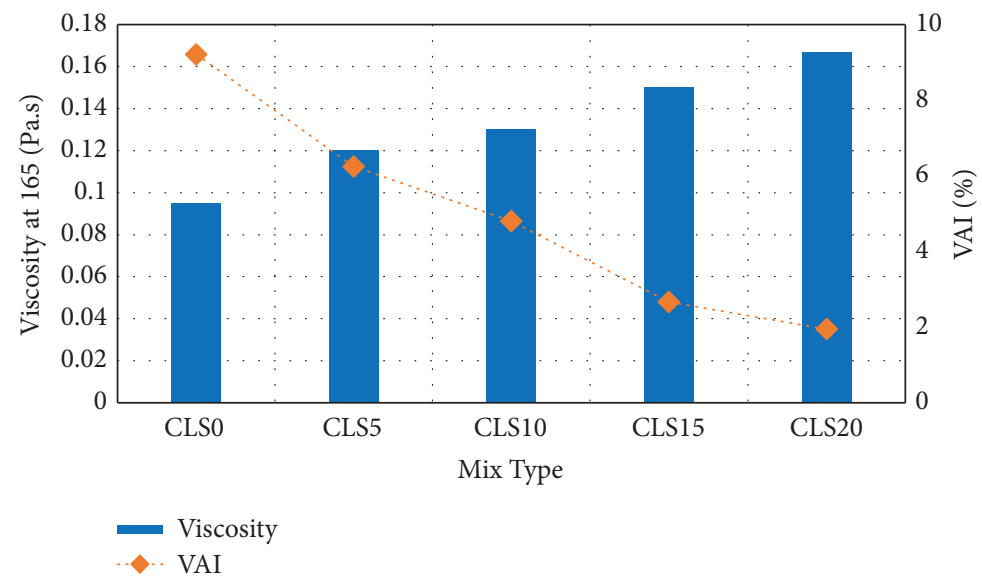

FIGURE 15: Rotational viscosity results and VAI values of bitumen samples (at $165^{\circ} \mathrm{C}$ ).

as the average of the three replicates. Figure 24 shows that the resins and aromatics consisted of the major part of bitumen's mass. Moreover, the addition of CLS within the bitumen dramatically increased the asphaltenes, leading to bitumen's stiffness. It is worth mentioning that CLS particles had a negative effect on the resins and aromatics. For example, as presented in Figure 24, the addition of 20\% CLS to the bitumen dwindled the aromatics and resins proportions from $32.93 \%$ to $27.95 \%$ and from $38.9 \%$ to $34.48 \%$, respectively. As depicted in Figure 25, although the aging process could increase the 


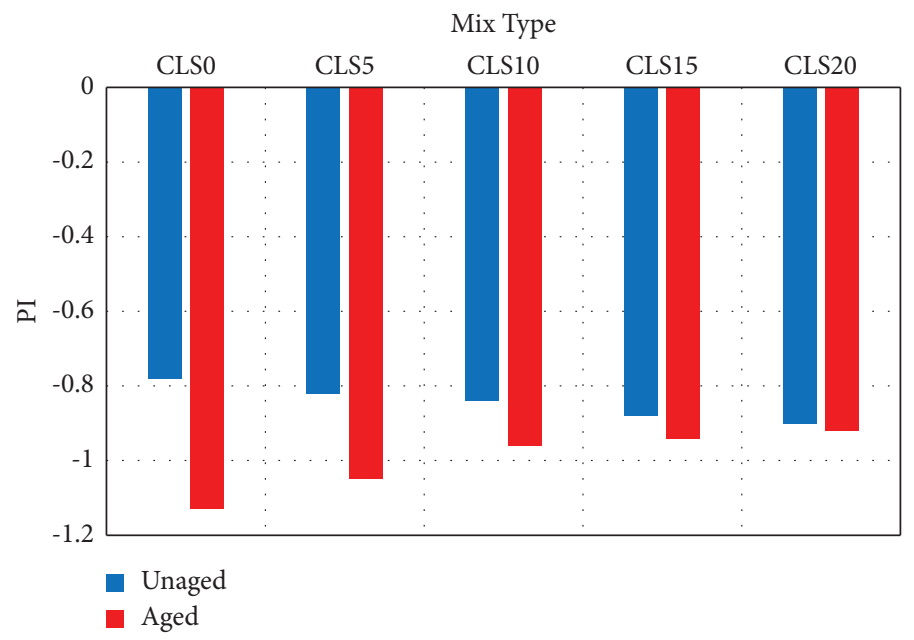

Figure 16: PI values of different mix types.

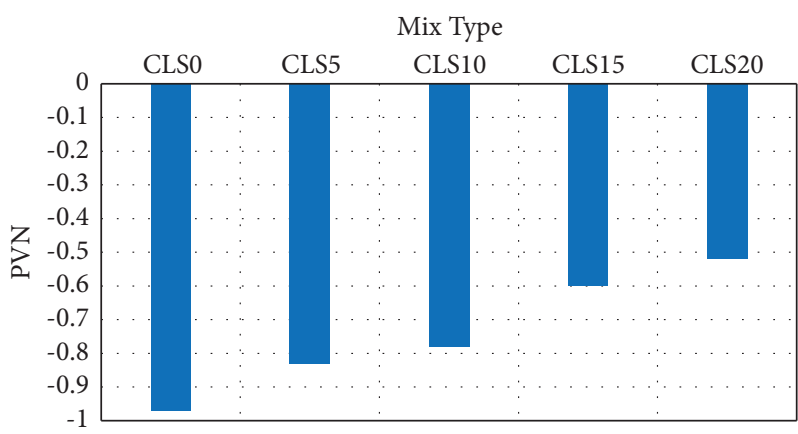

Figure 17: PVN values of different mix types.

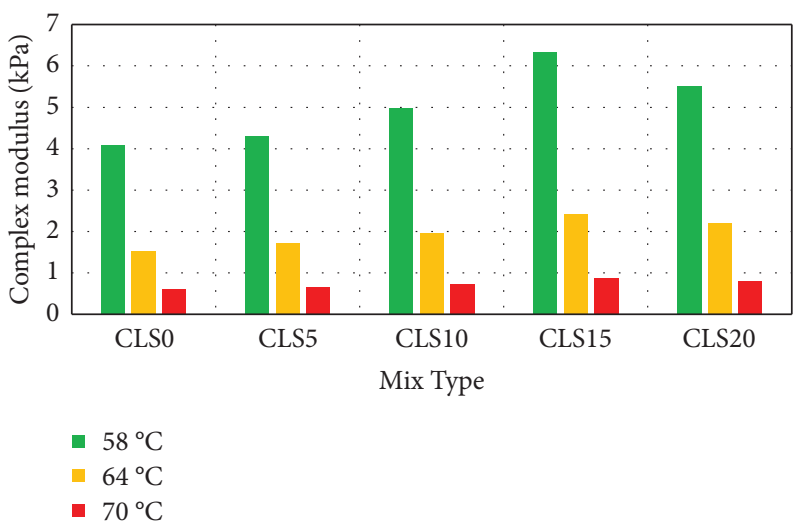

FIGURE 18: Effect of temperature levels and CLS content on the complex modulus of bitumen samples before aging. 


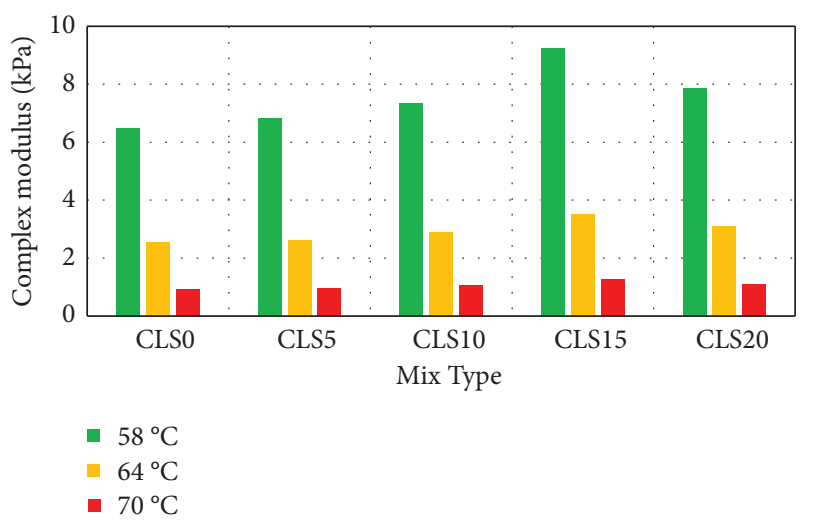

FIGURE 19: Effect of temperature levels and CLS content on the complex modulus of bitumen samples after aging.

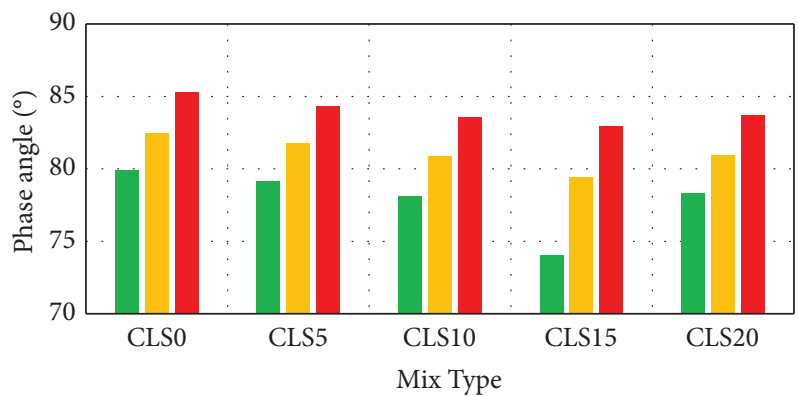

$$
\begin{array}{r}
-58^{\circ} \mathrm{C} \\
-\quad 64^{\circ} \mathrm{C} \\
-\quad 70^{\circ} \mathrm{C}
\end{array}
$$

Figure 20: Phase angle of bitumen samples at $51^{\circ} \mathrm{C}, 64^{\circ} \mathrm{C}$, and $70^{\circ} \mathrm{C}$ before aging.

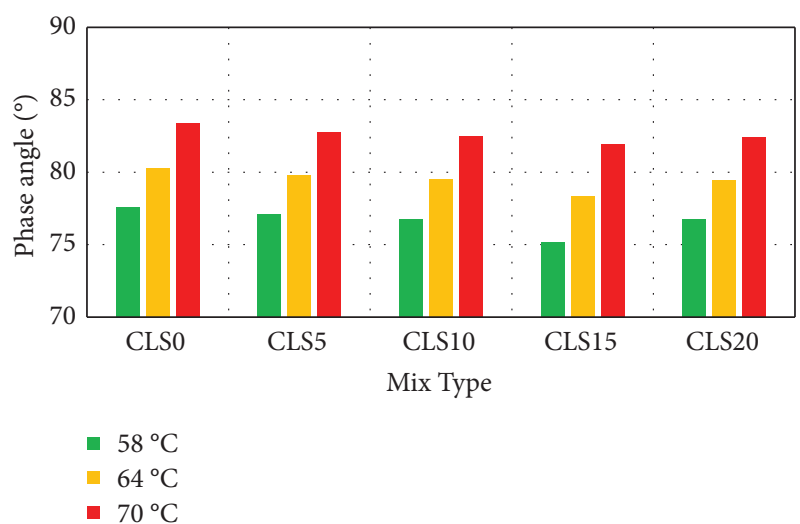

FIgURe 21: Phase angle of bitumen samples at $51^{\circ} \mathrm{C}, 64^{\circ} \mathrm{C}$, and $70^{\circ} \mathrm{C}$ after aging. 


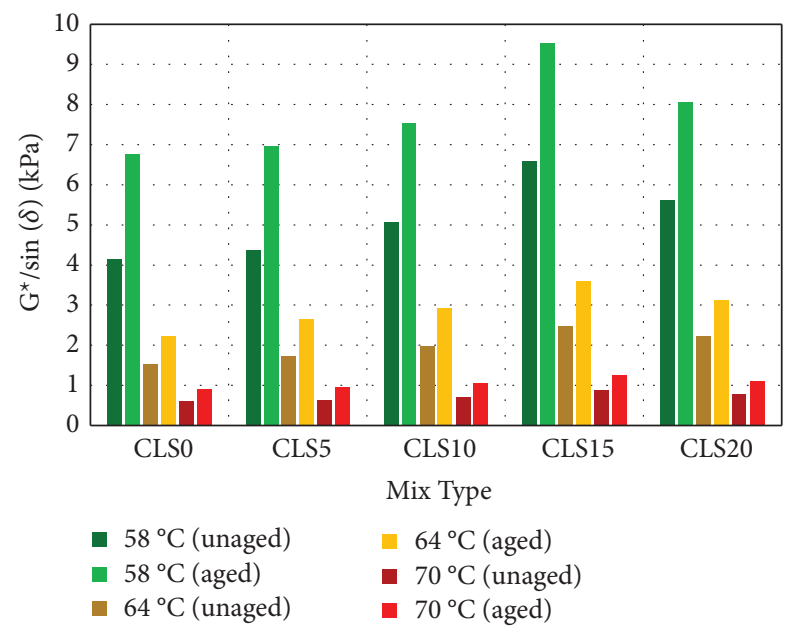

FIGURE 22: Effect of aging on the rutting factor values of bitumen samples.

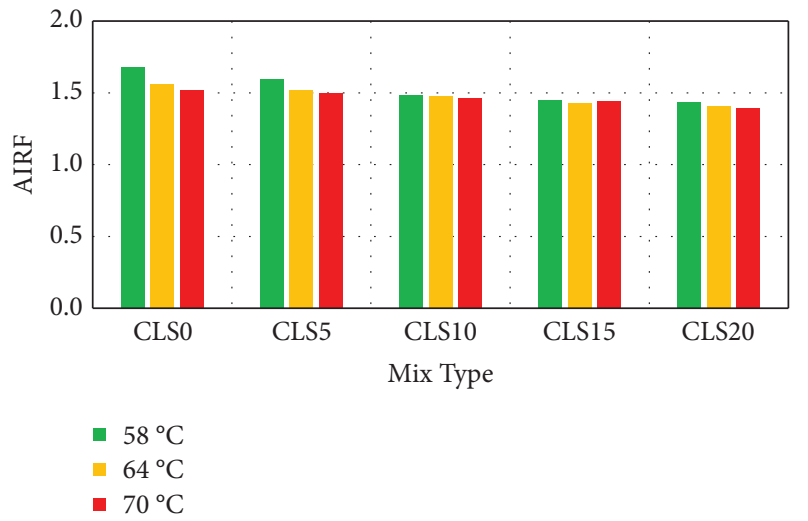

Figure 23: AIRF index of bitumen samples at different temperatures.

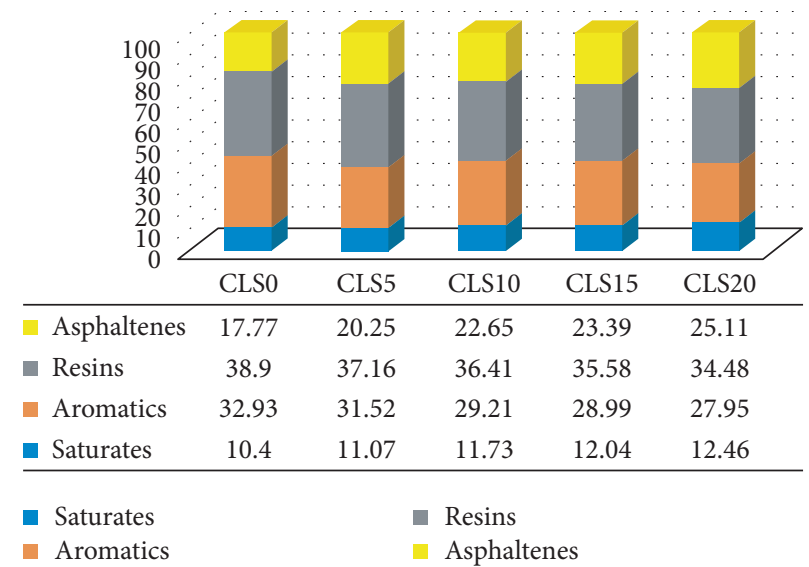

FIgURE 24: SARA fractions in virgin and CLS-modified bitumen samples before aging. 


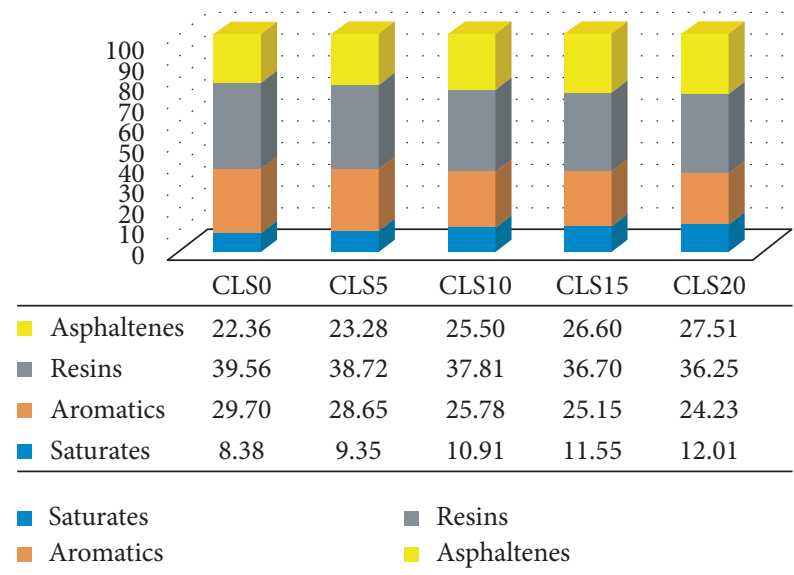

FIGURE 25: SARA fractions in virgin and CLS-modified bitumen samples after aging.

proportion of asphaltenes and resins, it negatively affected the aromatics and saturates. However, as the CLS content increased within the bitumen, the formation speed of asphaltenes dwindled. As a result, CLS could alleviate the bitumen's stiffness emanated from the aging process.

\section{Conclusions}

This research conducted various laboratory tests to characterize and compare the properties of bitumen samples modified with five different dosages of CLS. Moreover, the antiaging effect of CLS within the bitumen was investigated according to a series of aging indices emanated from the comparison of results between aged samples and virgin specimens. The following major conclusions are achieved based on the analysis and results of this laboratory investigation.

(i) The CLS particles contained a spherical shape with a bumpy surface. Although the virgin bitumen had a smooth surface, the surface texture of CLSmodified bitumen was porous. And, the CLS powder had high solubility potential into the bitumen.

(ii) The increase of CLS into the bitumen led to an increase in bitumen rigidity. Then, CLS-modified samples could more resist against rutting failure compared with the virgin bitumen. The PRP and SPI indices showed that the increase of bitumen rigidity, which emanated from the aging process, could be controlled by the CLS powder. The CLS-modified bitumen, which contained 15\% CLS, showed the highest PRP value and the lowest SPI value among all bitumen samples. As a result, 15\% CLS provided the highest antiaging potential within the bitumen.

(iii) The torsional recovery test showed that CLS incorporation degraded the bitumen's fatigue life at low-intermediate temperature conditions. Moreover, the brittleness of bitumen increased as the CLS content increased. (iv) At high temperatures, the presence of CLS enhanced the bitumen's consistency against permanent deformation. Although CLS raised the stiffness of bitumen, the CLS powder could not negatively affect the bitumen's workability. The lowest VAI was achieved for the CLS15 mix type. Then, 15\% CLS had the highest impact on the antiaging behavior of bitumen.

(v) The aging process and CLS incorporation negatively affected the bitumen's hardening, which led to the bitumen's brittleness at low-temperature conditions. However, bitumen's thermal susceptibility increment dwindled when the CLS content increased.

(vi) Based on the complex modulus $\left(G^{*}\right)$ and phase angle $(\delta)$ obtained by the DSR test, it can be concluded that there was a significant improvement of rutting resistance for the CLS-modified bitumen compared to the virgin bitumen at high-temperature levels. The CLS-to-bitumen (CLS/b) ratio of 0.15 achieved the optimum value for complex modulus $\left(G^{*}\right)$ and phase angle $(\delta)$; therefore, the most rutting resistance gained for the bitumen prepared by $15 \%$ CLS. The AIRF index expressed that the CLS could bring the antiaging potential for bitumen.

(vii) The incorporation of CLS into the bitumen changed the distribution of bitumen's SARA fractions. The addition of CLS to the bitumen decreased the fraction of resins and aromatics compared to the virgin bitumen. Moreover, the fraction of asphaltenes and saturates increased within the bitumen because of CLS incorporation. Then, CLS could increase bitumen's hardening. However, the presence of CLS within the bitumen dwindled the formation speed of asphaltenes during the aging process. That meant CLS could hinder the oxidative aging in bitumen.

\section{Data Availability}

At present, the data used to substantiate and corroborate the conclusions of this research are under prohibition because of restriction and privacy rules. Three months after the publication of this research, the corresponding author will be able to consider the requests for outputs.

\section{Disclosure}

This research did not receive any specific grant from funding agencies in the public, commercial, or not-for-profit sectors.

\section{Conflicts of Interest}

The authors declare that there are no conflicts of interest regarding the publication of this paper.

\section{References}

[1] D. Barić, H. Pilko, and J. Strujić, "An analytic hierarchy process model to evaluate road section design," Transport, vol. 31, pp. 312-321, 2016. 
[2] A. Quium, "Transport corridors for wider socio-economic development," Sustainability, vol. 11, no. 19, p. 5248, 2019.

[3] A. Bigazzi, G. Gill, and M. Winters, "Contrasting perspectives on the comfort and safety of pedestrians interacting with other road users," Transportation Research Record: Journal of the Transportation Research Board, vol. 2675, no. 3, pp. 33-43, 2021.

[4] H. Pérez-Acebo, H. Gonzalo-Orden, D. J. Findley, and E. Rojí, "Modeling the international roughness index performance on semi-rigid pavements in single carriageway roads," Construction and Building Materials, vol. 272, Article ID 121665, 2021.

[5] P. Zapata and J. A. Gambatese, "Energy consumption of asphalt and reinforced concrete pavement materials and construction," Journal of Infrastructure Systems, vol. 11, no. 1, pp. 9-20, 2005.

[6] S. Ling, F. Yu, D. Sun, G. Sun, and L. Xu, "A comprehensive review of tire-pavement noise: generation mechanism, measurement methods, and quiet asphalt pavement," Journal of Cleaner Production, vol. 287, Article ID 125056, 2021.

[7] M. Marzouk and M. M. Ashmawy, "Assessment of highways concrete and asphalt pavements using superiority inferiority ranking technique," Construction Innovation, vol. 21, no. 2, pp. 259-278, 2021.

[8] C. Miller, D. N. Little, A. Bhasin, N. Gardner, and B. Herbert, "Surface energy characteristics and impact of natural minerals on aggregate-bitumen bond strengths and asphalt mixture durability," Transportation Research Record: Journal of the Transportation Research Board, vol. 2267, no. 1, pp. 45-55, 2012.

[9] H. R. Jahanian, G. Shafabakhsh, and H. Divandari, "Performance evaluation of hot mix asphalt (HMA) containing bitumen modified with gilsonite," Construction and Building Materials, vol. 131, pp. 156-164, 2017.

[10] J. Neji, A. Siala, S. El Euch Khay, and A. Loulizi, "Reduction of bitumen content and production temperature of hot-mix asphalt incorporating RAP using dune sand and lime," RILEM Bookseries, vol. 27, pp. 1527-1533, 2022.

[11] A. N. Sawarkar, "Cavitation induced upgrading of heavy oil and bottom-of-the-barrel: a review," Ultrasonics Sonochemistry, vol. 58, Article ID 104690, 2019.

[12] A. R. Pasandín and I. Pérez, "The influence of the mineral filler on the adhesion between aggregates and bitumen," International Journal of Adhesion and Adhesives, vol. 58, pp. 53-58, 2015.

[13] D. Oldham, R. Mallick, and E. H. Fini, "Reducing susceptibility to moisture damage in asphalt pavements using polyethylene terephthalate and sodium montmorillonite clay," Construction and Building Materials, vol. 269, Article ID 121302, 2021.

[14] K. Lou, A. Kang, P. Xiao, Z. Wu, B. Li, and X. Wang, "Effects of basalt fiber coated with different sizing agents on performance and microstructures of asphalt mixture," Construction and Building Materials, vol. 266, Article ID 121155, 2021.

[15] A. Abouelsaad and G. White, "Review of asphalt mixture ravelling mechanisms, causes and testing," Int. J. Pavement Res. Technol., pp. 1-15, 2021.

[16] I. Menapace, W. Yiming, and E. Masad, "Effects of environmental factors on the chemical composition of asphalt binders," Energy \& Fuels, vol. 33, no. 4, pp. 2614-2624, 2019.

[17] Y. Qiao, J. Santos, A. M. K. Stoner, and G. Flinstch, "Climate change impacts on asphalt road pavement construction and maintenance: an economic life cycle assessment of adaptation measures in the State of Virginia, United States," Journal of Industrial Ecology, vol. 24, no. 2, pp. 342-355, 2020.

[18] J. Liu, Z. Wang, R. Luo, G. Bian, Q. Liang, and F. Yan, "Changes of components and rheological properties of bitumen under dynamic thermal aging," Construction and Building Materials, vol. 303, Article ID 124501, 2021.

[19] H. Wang, X. Liu, P. Apostolidis, M. van de Ven, S. Erkens, and A. Skarpas, "Effect of laboratory aging on chemistry and rheology of crumb rubber modified bitumen," Mater. Struct. Constr.vol. 53, pp. 1-15, 2020.

[20] S. Weigel and D. Stephan, "Modelling of rheological and ageing properties of bitumen based on its chemical structure," Mater. Struct. Constr.vol. 50, pp. 1-15, 2017.

[21] H. Wang, X. Liu, P. Apostolidis, and T. Scarpas, "Rheological behavior and its chemical interpretation of crumb rubber modified asphalt containing warm-mix additives," Transportation Research Record: Journal of the Transportation Research Board, vol. 2672, no. 28, pp. 337-348, 2018.

[22] S. Rudyk, "Relationships between SARA fractions of conventional oil, heavy oil, natural bitumen and residues," Fuel, vol. 216, pp. 330-340, 2018.

[23] X. Qu, Q. Liu, M. Guo, D. Wang, and M. Oeser, "Study on the effect of aging on physical properties of asphalt binder from a microscale perspective," Construction and Building Materials, vol. 187, pp. 718-729, 2018.

[24] A. Ghasemirad, N. Bala, and L. Hashemian, "High-temperature performance evaluation of asphaltenes-modified asphalt binders," Molecules, vol. 25, no. 15, p. 3326, 2020.

[25] F. Handle, M. Harir, J. Füssl et al., "Tracking aging of bitumen and its saturate, aromatic, resin, and asphaltene fractions using high-field fourier transform ion cyclotron resonance mass spectrometry," Energy \& Fuels, vol. 31, no. 5, pp. 4771-4779, 2017.

[26] T. Zhou, L. Cao, E. H. Fini, L. Li, Z. Liu, and Z. Dong, "Behaviors of asphalt under certain aging levels and effects of rejuvenation," Construction and Building Materials, vol. 249, Article ID 118748, 2020.

[27] I. G. d. N. Camargo, T. B. Dhia, A. Loulizi, B. Hofko, and J. Mirwald, "Anti-aging additives: proposed evaluation process based on literature review," Road Materials and Pavement Design, vol. 22, no. sup1, pp. S134-S153, 2021.

[28] İ. Gökalp and V. E. Uz, "Utilizing of waste vegetable cooking oil in bitumen: zero tolerance aging approach," Construction and Building Materials, vol. 227, Article ID 116695, 2019.

[29] T. Geçkil, "Physical, chemical, microstructural and rheological properties of reactive terpolymer-modified bitumen," Materials, vol. 16, p. 921, 2019.

[30] S. Hassanpour-Kasanagh, P. Ahmedzade, A. M. Fainleib, and A. Behnood, "Rheological properties of asphalt binders modified with recycled materials: a comparison with StyreneButadiene-Styrene (SBS)," Construction and Building Materials, vol. 230, Article ID 117047, 2020.

[31] C. Ouyang, S. Wang, Y. Zhang, and Y. Zhang, "Improving the aging resistance of styrene-butadiene-styrene tri-block copolymer modified asphalt by addition of antioxidants," Polymer Degradation and Stability, vol. 91, no. 4, pp. 795-804, 2006.

[32] J. Zhang, J. Wang, Y. Wu, Y. Wang, and Y. Wang, "Evaluation of the improved properties of SBR/weathered coal modified bitumen containing carbon black," Construction and Building Materials, vol. 23, no. 7, pp. 2678-2687, 2009.

[33] Z. You, J. Mills-Beale, J. M. Foley et al., "Nanoclay-modified asphalt materials: preparation and characterization," 
Construction and Building Materials, vol. 25, no. 2, pp. 1072-1078, 2011.

[34] M. Zahoor, S. Nizamuddin, S. Madapusi, and F. Giustozzi, "Sustainable asphalt rejuvenation using waste cooking oil: a comprehensive review," Journal of Cleaner Production, vol. 278, Article ID 123304, 2021.

[35] D. Wang, Z. Cai, Z. Zhang, X. Xu, and H. Yu, "Laboratory investigation of lignocellulosic biomass as performance improver for bituminous materials," Polymers, vol. 11, no. 8, p. 1253, 2019.

[36] F. Ma, J. Dai, Z. Fu et al., "Biochar for asphalt modification: a case of high-temperature properties improvement," The Science of the Total Environment, vol. 804, Article ID 150194, 2022.

[37] E. Chailleux, M. Audo, S. Goyer, C. Queffelec, and O. Marzouk, "Advances in the development of alternative binders from biomass for the production of biosourced road binders," Advances in Asphalt Materials, pp. 347-362, 2015.

[38] R. Penki and S. K. Rout, "Next-generation bitumen: a review on challenges and recent developments in bio-bitumen preparation and usage," Biomass Convers. Biorefinery, pp. 118,2021

[39] J. Yu, M. Vaidya, G. Su, S. Adhikari, E. Korolev, and S. Shekhovtsova, "Experimental study of soda lignin powder as an asphalt modifier for a sustainable pavement material," Construction and Building Materials, vol. 298, Article ID 123884, 2021.

[40] J. Hu, Q. Zhang, and D.-J. Lee, "Kraft lignin biorefinery: a perspective," Bioresource Technology, vol. 247, pp. 1181-1183, 2018.

[41] Y.-X. Pang, X.-Q. Qiu, D.-J. Yang, and H.-M. Lou, "Influence of oxidation, hydroxymethylation and sulfomethylation on the physicochemical properties of calcium lignosulfonate," Colloids and Surfaces A: Physicochemical and Engineering Aspects, vol. 312, no. 2-3, pp. 154-159, 2008.

[42] A. O. Gezerman and B. D. Çorbacioglu, "Effects of calcium lignosulfonate and silicic acid on ammonium nitrate degradation," Journal of Chemistry, vol. 2014, 2014.

[43] Y. Zhang, X. Wang, G. Ji et al., "Mechanical performance characterization of lignin-modified asphalt mixture," Applied Sciences, vol. 10, no. 9, p. 3324, 2020.

[44] M. Mazumder, R. Ahmed, A. Wajahat Ali, and S.-J. Lee, "SEM and ESEM techniques used for analysis of asphalt binder and mixture: a state of the art review," Construction and Building Materials, vol. 186, pp. 313-329, 2018.

[45] W. Huang, Y. Guo, Y. Zheng et al., "Chemical and rheological characteristics of rejuvenated bitumen with typical rejuvenators," Construction and Building Materials, vol. 273, Article ID 121525, 2021.

[46] M. Blanco, S. Maspoch, I. Villarroya, X. Peralta, J. M. González, and J. Torres, "Determination of the penetration value of bitumens by near infrared spectroscopy," The Analyst, vol. 125, no. 10, pp. 1823-1828, 2000.

[47] F. Moghadas Nejad, A. R. Azarhoosh, G. H. Hamedi, and M. J. Azarhoosh, "Influence of using nonmaterial to reduce the moisture susceptibility of hot mix asphalt," Construction and Building Materials, vol. 31, pp. 384-388, 2012.

[48] J.-S. Chen and K.-Y. Lin, "Mechanism and behavior of bitumen strength reinforcement using fibers," Journal of Materials Science, vol. 40, no. 1, pp. 87-95, 2005.

[49] A. Al-Sabaeei, M. Napiah, M. Sutanto, and W. Alaloul, "Effects of Waste Denim Fibre (WDF) on the physical and rheological properties of bitumen," IOP Conference Series:
Materials Science and Engineering, vol. 527, Article ID 012047, 2019.

[50] T. W. Kim, J. Baek, H. J. Lee, and J. Y. Choi, "Fatigue performance evaluation of SBS modified mastic asphalt mixtures," Construction and Building Materials, vol. 48, pp. 908-916, 2013.

[51] S. G. Jahromi and A. Khodaii, "Effects of nanoclay on rheological properties of bitumen binder," Construction and Building Materials, vol. 23, no. 8, pp. 2894-2904, 2009.

[52] B. Singh, L. Kumar, M. Gupta, and G. S. Chauhan, "Polymermodified bitumen of recycled LDPE and maleated bitumen," Journal of Applied Polymer Science, vol. 127, no. 1, pp. 67-78, 2013.

[53] A. Alisov, C. Riccardi, J. Schrader, A. Cannone Falchetto, and M. P. Wistuba, "A novel method to characterise asphalt binder at high temperature," Road Materials and Pavement Design, vol. 21, no. 1, pp. 143-155, 2020.

[54] C. Varanda, I. Portugal, J. Ribeiro, A. M. Silva, and C. M. Silva, "Influence of polyphosphoric acid on the consistency and composition of formulated bitumen: standard characterization and NMR insights," Journal of analytical methods in chemistry, vol. 2016, Article ID 2915467, 2016.

[55] G. White, "A synthesis on the effects of two commercial recycled plastics on the properties of bitumen and asphalt," Sustainable Times, vol. 12, pp. 1-20, 2020.

[56] A. H. Ibrahim, M. R. Mohd Hasan, A. Sani et al., "Physicomechanical assessments and heavy metals' leaching potential of modified asphalt binders incorporating crumb rubber and tin slag powders," Advances in Materials Science and Engineering, vol. 2021, 2021.

[57] S. Poovaneshvaran, M. R. Mohd Hasan, and R. Putra Jaya, "Impacts of recycled crumb rubber powder and natural rubber latex on the modified asphalt rheological behaviour, bonding, and resistance to shear," Construction and Building Materials, vol. 234, Article ID 117357, 2020.

[58] M. El-Shafie, I. M. Ibrahim, and A. M. M. Abd El Rahman, "The addition effects of macro and nano clay on the performance of asphalt binder," Egyptian Journal of Petroleum, vol. 21, no. 2, pp. 149-154, 2012.

[59] J.-s. Park, D.-b. Kim, K.-h. Oh, and S.-k. Oh, "Field evaluation of Synthetic Polymer Rubber Gel through filler content and oil leakage mass measurement," Applied Sciences, vol. 8, no. 6, p. 896, 2018.

[60] H. F. Haghshenas, R. Rea, D. Byre, D. F. Haghshenas, G. Reinke, and M. Zaumanis, "Asphalt binder laboratory short-term aging: effective parameters and new protocol for testing," Journal of Materials in Civil Engineering, vol. 32, Article ID 04019327, 2020.

[61] Y. Lin, C. Hu, S. Adhikari, C. Wu, and M. Yu, "Evaluation of waste express bag as a novel bitumen modifier," Applied Sciences, vol. 9, no. 6, p. 1242, 2019.

[62] P. Ahmedzade, A. Fainleib, T. Günay, and O. Grygoryeva, "Modification of bitumen by electron beam irradiated recycled low density polyethylene," Construction and Building Materials, vol. 69, pp. 1-9, 2014.

[63] M. Mirsepahi, J. Tanzadeh, and S. A. Ghanoon, "Laboratory evaluation of dynamic performance and viscosity improvement in modified bitumen by combining nanomaterials and polymer," Construction and Building Materials, vol. 233, Article ID 117183, 2020.

[64] M. Ameri, M. Vamegh, R. Imaninasab, and H. Rooholamini, "Effect of nanoclay on performance of neat and SBS-modified bitumen and HMA," Petroleum Science and Technology, vol. 34, no. 11-12, pp. 1091-1097, 2016. 
[65] H. Yaacob, M. Ali Mughal, R. P. Jaya, M. R. Hainin, D. S. Jayanti, and C. N. Che Wan, "Rheological properties of styrene butadiene rubber modified bitumen binder," J. Teknol.vol. 78, pp. 121-126, 2016.

[66] S. S. Galooyak, B. Dabir, A. E. Nazarbeygi, and A. Moeini, "Rheological properties and storage stability of bitumen/SBS/ montmorillonite composites," Construction and Building Materials, vol. 24, no. 3, pp. 300-307, 2010.

[67] S. Rezaei, H. Ziari, and S. Nowbakht, "Low temperature functional analysis of bitumen modified with composite of nano-SiO2and styrene butadiene styrene polymer," Petroleum Science and Technology, vol. 34, no. 5, pp. 415-421, 2016.

[68] R. N. A. Raja Zulkefli, H. Yaacob, R. Putra Jaya et al., "Effect of different sizes of palm oil fuel ash (POFA) towards physical properties of modified bitumen," IOP Conference Series: Earth and Environmental Science, vol. 140, Article ID 012108, 2018.

[69] S. Abdulrahman, M. R. Hainin, M. K. Idham et al., "Physical properties of warm cup lump modified bitumen," IOP Conference Series: Materials Science and Engineering, vol. 527, Article ID 012048, 2019.

[70] S. N. A. Jeffry, R. P. Jaya, N. A. Hassan, H. Yaacob, J. Mirza, and S. H. Drahman, "Effects of nanocharcoal coconut-shell ash on the physical and rheological properties of bitumen," Construction and Building Materials, vol. 158, pp. 1-10, 2018.

[71] S. H. Firoozifar, S. Foroutan, and S. Foroutan, "The effect of asphaltene on thermal properties of bitumen," Chemical Engineering Research and Design, vol. 89, no. 10, pp. 20442048, 2011.

[72] I. M. Khan, S. Kabir, M. A. Alhussain, and F. F. Almansoor, "Asphalt design using recycled plastic and crumb-rubber waste for sustainable pavement construction," Procedia Engineering, vol. 145, pp. 1557-1564, 2016.

[73] L. Zhang, C. Xing, F. Gao, T.-s. Li, and Y.-q. Tan, "Using DSR and MSCR tests to characterize high temperature performance of different rubber modified asphalt," Construction and Building Materials, vol. 127, pp. 466-474, 2016.

[74] G. G. Al-Khateeb and N. M. Al-Akhras, "Properties of Portland cement-modified asphalt binder using Superpave tests," Construction and Building Materials, vol. 25, no. 2, pp. 926-932, 2011.

[75] T. Geckil, P. Ahmedzade, and T. Alatas, "Effect of carbon black on the high and low temperature properties of bitumen," International Journal of Civil Engineering, vol. 16, no. 2, pp. 207-218, 2018.

[76] T. Geckil and M. Seloglu, "Performance properties of asphalt modified with reactive terpolymer," Construction and Building Materials, vol. 173, pp. 262-271, 2018.

[77] S. Matolia, G. Guduru, B. Gottumukkala, and K. K. Kuna, “An investigation into the influence of aging and rejuvenation on surface free energy components and chemical composition of bitumen," Construction and Building Materials, vol. 245, Article ID 118378, 2020.

[78] S. Ren, X. Liu, Y. Zhang et al., "Multi-scale characterization of lignin modified bitumen using experimental and molecular dynamics simulation methods," Construction and Building Materials, vol. 287, Article ID 123058, 2021.

[79] P. Redelius, "Asphaltenes in bitumen, what they are and what they are not," Road Materials and Pavement Design, vol. 10, no. SI, pp. 25-43, 2009.

[80] T. Gentzis, P. Rahimi, R. Malhotra, and A. S. Hirschon, "The effect of carbon additives on the mesophase induction period of Athabasca bitumen," Fuel Processing Technology, vol. 69, no. 3, pp. 191-203, 2001.
[81] Y. Cheng, J. Tao, Y. Jiao, Q. Guo, and C. Li, "Influence of diatomite and mineral powder on thermal oxidative ageing properties of asphalt," Advances in Materials Science and Engineering, vol. 2015, 2015.

[82] C. Zhang, J. Yu, T. Wang, S. Xu, C. Hu, and W. Duan, "Evaluation of ultraviolet aging resistance of bitumen modified with isobutyltriethoxysilane surface organic grafted LDH," Construction and Building Materials, vol. 241, Article ID 118016, 2020.

[83] A. H. Ali, N. S. Mashaan, and M. R. Karim, "Investigations of physical and rheological properties of aged rubberised bitumen," Advances in Materials Science and Engineering, vol. 2013, 2013.

[84] I. Amin, S. M. El-Badawy, T. Breakah, and M. H. Z. Ibrahim, "Laboratory evaluation of asphalt binder modified with carbon nanotubes for Egyptian climate," Construction and Building Materials, vol. 121, pp. 361-372, 2016.

[85] T. Günay and P. Ahmedzade, "Physical and rheological properties of nano-TiO2 and nanocomposite modified bitumens," Construction and Building Materials, vol. 243, Article ID 118208, 2020.

[86] K. Yan, S. Tian, J. Chen, and J. Liu, "High temperature rheological properties of APAO and EVA compound modified asphalt," Construction and Building Materials, vol. 233, Article ID 117246, 2020. 